\title{
Analisis Pengaruh On-Street Parking terhadap Kinerja Jalan di Pasar Jaya Ciracas, Jakarta Timur
}

\author{
Dicky Masrul $^{* 1}$, Adita Utami² \\ ${ }^{1,2}$ Program Studi Teknik Sipil, Universitas Pertamina, Jl. Teuku Nyak Arief Jakarta 12220 \\ E-mail: "1 masruldicky@gmail.com, ${ }^{2}$ adita.utami@ universitaspertamina.ac.id \\ Received 27 September 2021; Reviewed 11 October 2021; Accepted 04 November 2021 \\ Journal Homepage: http://jurnal.borneo.ac.id/index.php/borneoengineering
}

\begin{abstract}
This research contains an analysis of the traffic performance by dint of on-street parking, afterward the results are compared with the traffic performance if a scenario is made that there is no on-street parking activity. The purposes of this research are to determine the impact of on-street parking to road performance also to perceive the road level of service. The method used in this research is a quantitive method by direct field research. The results of this research are on-street parking activity around Jaya Ciracas Market affected the traffic performance with a difference in road capacity about 39,03\%. The value of the road level of service when there is on-street parking activity is $D$, while when on-street parking is abolished, the road level of service can increase to $C$.
\end{abstract}

Keywords: road performance, degree of saturation, level of service, road capacity

\begin{abstract}
Abstrak
Penelitian ini berisi mengenai analisis kinerja ruas jalan apabila dipengaruhi oleh kegiatan parkir pada badan jalan, kemudian hasil analisis tersebut dibandingkan dengan kinerja ruas jalan dengan skenario tidak terdapat kegiatan parkir pada badan jalan. Tujuan dari penelitian ini adalah untuk mengetahui pengaruh akibat adanya parkir pada badan jalan terhadap kinerja jalan serta mengetahui tingkat pelayanan jalan. Metode yang digunakan dalam penelitian ini adalah metode dengan data yang diperoleh langsung dari lapangan. Hasil dari penelitian ini adalah kegiatan parkir pada badan jalan di sekitar Pasar Jaya Ciracas berpengaruh terhadap kinerja jalan dengan perbedaan kapasitas jalan apabila terdapat kegiatan parkir pada badan jalan dengan tidak ada kegiatan parkir pada badan jalan sebesar 39,03\%. Dari hasil perhitungan, nilai tingkat pelayanan jalan apabila terdapat kegiatan parkir pada badan jalan adalah D, sementara apabila kegiatan parkir pada badan jalan ditiadakan maka tingkat pelayanan jalan dapat meningkat menjadi $C$.
\end{abstract}

Kata kunci: kinerja ruas jalan, derajat kejenuhan, tingkat pelayanan, kapasitas jalan

\section{Pendahuluan}

Kemacetan lalu lintas pada ruas jalan merupakan persoalan yang sering ditemui terutama di negara berkembang seperti Indonesia. Dikutip melalui situs TomTom Traffic Index, pada tahun 2020 Jakarta menduduki posisi ke-31 dari 416 kota dengan tingkat kemacetan tertinggi di dunia. Kemacetan umumnya terjadi pada daerah dengan pendayagunaan lahan serta jumlah penduduk yang sangat tinggi (Mustikarani \& Suherdiyanto, 2016). Banyak penyebab yang menjadi pemicu tersendatnya lalu lintas di suatu kawasan. Disadur melalui Boediningsih (2011), kemacetan dapat 
terjadi karena berbagai penyebab, diantaranya adalah pejalan kaki yang kurang tertib, transportasi umum yang berhenti tidak pada tempatnya untuk membawa penumpang, terdapat pedagang kaki lima atau pasar yang mendayagunakan sisi jalan untuk lokasi berjualan, serta terdapat pengendara yang memakai badan jalan sebagai tempat untuk memarkirkan kendaraannya.

Adanya kendaraan yang memanfaatkan badan jalan menjadi tempat parkir dapat mengakibatkan pergerakan kendaraan menjadi terhambat karena dapat menyebabkan penurunan kapasitas jalan sehingga performa jalan yang berfungsi untuk mendistribusikan arus lalu lintas akan menurun. Biasanya kegiatan parkir di badan jalan ini terjadi pada kawasan atau sentral kegiatan seperti pertokoan, rumah makan, kantor, serta pasar. Kegiatan parkir pada badan jalan dapat menyulitkan pengendara lainnya apabila tidak segera diberlakukan pengaturan yang baik dan benar. Salah satu daerah yang dapat ditemui aktivitas parkir pada badan jalan ialah Jalan Raya Ciracas. Apabila dilihat dari jenis jalannya, Jalan Raya Ciracas dirancang berupa jalan lokal primer dengan tipe jalan dua lajur dengan dua arah tak terbagi (2/2 TT). Di sepanjang Jalan Raya Ciracas terdapat perumahan, ruko, bank serta pasar sehingga ruas jalan tersebut banyak dilintasi oleh kendaraan. Salah satu pasar yang terletak di kawasan Jalan Raya Ciracas adalah Pasar Jaya Ciracas.

Pasar Jaya Ciracas merupakan kawasan perdagangan untuk memenuhi kebutuhan hidup sehari-hari yang menjual berbagai macam produk seperti produk hewani, aneka jenis sayuran, pakaian hingga alat-alat rumah tangga. Hadirnya Pasar Jaya Ciracas mendukung pemenuhan kebutuhan untuk masyarakat di sekitar Kecamatan Ciracas serta Cipayung. Saat ini, banyak sekali pengunjung pasar yang menggunakan kendaraan pribadi namun memarkirkan kendaraannya pada badan jalan di sekitar lokasi pasar. Kegiatan parkir pada badan jalan di sekitar Pasar Jaya Ciracas terjadi karena pengunjung pasar merasa lebih mudah serta cepat untuk melakukan kegiatan berbelanja. Selain itu, sebagian masyarakat juga enggan untuk memarkirkan kendaraannya di tempat parkir karena memperhitungkan biaya parkir yang dikenakan. Akibatnya tidak jarang arus lalu lintas di sekitar Pasar Jaya Ciracas (dari Citra Landmark Jakarta hingga Pasar Jaya Ciracas) menjadi terhambat karena kondisi tersebut. Melihat kondisi tersebut, penelitian ini perlu dilakukan guna menganalisis dampak akibat parkir pada badan jalan terhadap kinerja jalan di sekitar kawasan Pasar Jaya Ciracas.

\section{Metode Penelitian}

\subsection{Lokasi Penelitian}

Kegiatan survei pada penelitian ini berlokasi pada Jalan Raya Ciracas dengan batasan lokasi disekitar Pasar Jaya Ciracas.

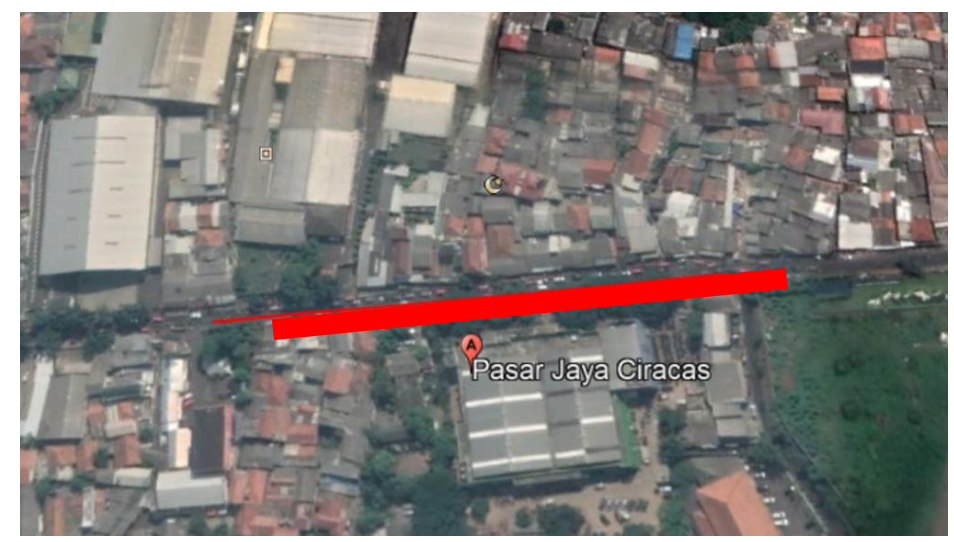

Gambar 1. Lokasi Penelitian

(Sumber: Google Earth Pro, diakses pada 21 Februari 2021) 
Jalan Raya Ciracas memiliki tipe jalan dua lajur dengan dua arah tak terbagi (2/2 TT) dengan satu lajur merupakan arah Jalan Raya Ciracas menuju Jalan Raya Bogor dan satu lajur lainnya arah sebaliknya. Pada ruas Jalan Raya Ciracas yang ditinjau, bahu jalan hanya terdapat pada lajur Jalan Raya Bogor menuju Jalan Raya Ciracas (tanpa trotoar), sementara pada lajur lainnya hanya terdapat trotoar (tanpa adanya baju jalan). Lokasi yang diteliti dapat diamati pada Gambar 1 dengan data-data umum yang diperoleh melalui survei langsung di area yang ditinjau.

1. Lebar masing-masing lajur : 3,35 meter

2. Lebar bahu jalan $\quad: 1,2$ meter (hanya pada satu sisi)

3. Lebar trotoar : 0,8 meter (hanya pada satu sisi)

4. Panjang jalan penelitian : 200 meter

\subsection{Metode Pengambilan Data}

Untuk pengambilan data guna kebutuhan analisis kinerja jalan seperti pengambilan data volume lalu lintas, kecepatan lalu lintas, serta hambatan samping perlu diadakan survei pendahuluan terlebih dahulu. Survei pendahuluan dilakukan pada hari Senin hingga Minggu dengan waktu pengamatan selama lima jam. Survei pendahuluan sendiri berfungsi untuk mengetahui volume lalu lintas terpadat dalam satu pekan. Dari hasil pengamatan dapat diketahui bahwa hari Jumat merupakan hari dengan volume lalu lintas terpadat di kawasan tersebut dibandingkan dengan hari lainnya. Sehingga hari Jumat diharapkan mampu mewakili kondisi lalu lintas terpadat pada ruas jalan tersebut.

\subsection{Metode Pengolahan Data}

Sesudah keseluruhan data terhimpun, selanjutnya pengolahan data dapat dilakukan yakni:

\subsubsection{Pengolahan data terkait dengan volume lalu lintas}

Data volume lalu lintas didapatkan dengan menghitung kuantitas kendaraan yang melewati suatu titik yang sudah ditetapkan dalam kurun waktu tertentu. Data volume lalu lintas diolah dengan mentransformasikan tiap jenis kendaraan ke dalam satuan mobil penumpang (smp) berdasarkan dengan nilai ekivalen kendaraan ringan (ekr) yang disadur melalui Pedoman Kapasitas Jalan Indonesia tahun 2014. Besaran nilai ekr sendiri dipengaruhi oleh beberapa aspek, seperti kondisi medan jalan (dataran, berliku atau pegunungan), keadaan pengendalian lalu lintas, serta tingkat lalu lintas (Yeung, Wong, \& Secadiningrat, 2015). Nilai volume lalu lintas dapat diperoleh menggunakan persamaan 1 .

$$
V(\mathrm{smp} / \mathrm{jam})=(K R \times e k r)+(K B \times e k r)+(S M \times e k r)
$$

\section{Keterangan:}

$V \quad=\quad$ Volume lalu lintas

$K R=$ Kendaraan ringan, terdiri dari kendaraan bermotor ber as dua dengan empat buah roda dengan jarak 2,0-3,0 (seperti mobil pribadi, oplet, mobil pick up, serta truk kecil)

$K B=$ Kendaraan berat, terdiri dari kendaraan bermotor lebih dari 4 roda (seperti bus, truk 2 as, truk 3 as, serta truk kombinasi)

$S M \quad=\quad$ Kendaraan roda dua atau tiga

\subsubsection{Pengolahan data terkait dengan bobot hambatan samping}

Adanya kegiatan hambatan samping dapat berpengaruh terhadap kelancaran arus lalu lintas sehingga mampu menyebabkan penurunan kinerja suatu ruas jalan (Syaputra, Sebayang, \& Herianto, 2016). Data hambatan samping diolah dengan mengkonversikan nilai bobot kejadian pejalan kaki, kendaraan parkir/berhenti, kendaraan keluar/masuk sisi jalan, serta kendaraan lambat 
dengan masing-masing faktor bobot agar didapatkan kategori hambatan samping serta dapat menghitung kecepatan arus bebas.

\subsubsection{Pengolahan data terkait dengan waktu tempuh kendaraan}

Data waktu tempuh tiap jenis kendaraan diproses menjadi kecepatan setempat rata-rata untuk setiap jam dengan mengaplikasikan metode kecepatan rata-rata ruang (space mean speed).

\subsection{Metode Analisis Data}

Sesudah dilakukan pengolahan data, kemudian data-data tersebut dianalisis dan diteruskan dengan membahas hasil analisis. Tahapan analisis yang dikerjakan pada penelitian ini meliputi kecepatan arus bebas, kecepatan rata-rata ruang, kepadatan jalan, kapasitas ruas jalan, derajat kejenuhan, dan tingkat pelayanan jalan.

\subsubsection{Kecepatan Arus Bebas}

Dikutip melalui Direktorat Jenderal Bina Marga (2014), kecepatan arus bebas $\left(V_{B}\right)$ yakni kecepatan sebuah kendaraan tanpa dipengaruhi (tidak terganggu) oleh kendaraan lainnya atau dengan kata lain, pengendara bepergian dengan keadaan yang nyaman terhadap situasi geometrik, lingkungan, serta penataan lalu lintas yang ada. Nilai $V_{B}$ dapat dihitung menggunakan persamaan 2 .

$$
V_{B}=\left(V_{B D}+V_{B L}\right) \times F V_{B H S} \times F V_{B U K}
$$

Keterangan:

$V_{B} \quad=\quad$ Kecepatan arus bebas kendaraan ringan pada kondisi lapangan $(\mathrm{km} / \mathrm{jam})$

$V_{B D}=$ Kecepatan arus bebas dasar kendaraan ringan pada jalan yang ditinjau (km/jam)

$V_{B L}=$ Adaptasi kecepatan terhadap lebar jalan $(\mathrm{km} / \mathrm{jam})$

$F V_{B H S}=\quad$ Nilai penyetaraan terhadap hambatan samping

$F V_{B U K}=\quad$ Nilai penyetaraan kecepatan terhadap jumlah penduduk

\subsubsection{Kecepatan Rata-Rata Ruang}

Kecepatan rata-rata ruang atau space mean speed (SMS) ialah kecepatan rata-rata dari seluruh kendaraan yang melewati bagian jalan dalam kurun waktu tertentu (Sari, Oktaviani, \& Novia, 2015). Persamaan untuk menghitung nilai kecepatan rata-rata ruang yakni sebagai berikut:

$$
V s=\frac{L}{\sum_{i=1}^{n} \frac{t i}{n}}=\frac{n L}{\sum_{i=1}^{n} t i}
$$

Keterangan:

$\begin{array}{lll}V S & = & \text { Kecepatan melintas rata-rata }(\mathrm{km} / \mathrm{jam} ; \mathrm{m} / \mathrm{dtk}) \\ L & = & \text { Panjang segmen jalan }(\mathrm{km} ; \mathrm{m}) \\ t i & = & \text { Waktu tempuh kendaraan ke-i } \\ n & = & \text { Total waktu pengamatan }\end{array}$

\subsubsection{Kepadatan Jalan}

Disadur melalui Sulastri \& Firdaus (2018), kepadatan (density) yakni banyaknya kendaraan yang mendiami kawasan jalan dengan panjang yang terbatas. Nilai ini dapat dituliskan sebagai jumlah kendaraan per kilometer (smp/km). Nilai kepadatan dapat dihitung menggunakan persamaan 4 .

$$
K=\frac{\text { Volume }}{\text { Kecepatan rata-rata ruang }}
$$




\subsubsection{Kapasitas Ruas Jalan}

Kapasitas suatu ruas jalan yakni arus tertinggi yang mampu ditunjang suatu ruas jalan per satuan jam pada keadaan tertentu (Utami \& Widyastuti, 2019). Apabila terdapat perbedaan yang signifikan antara nilai kapasitas dengan volume lalu lintas maka dapat menyebabkan permasalahan di ruas jalan tersebut (Lestari \& Apriyani, 2014). Nilai kapasitas ruas jalan dapat dihitung menggunakan persamaan 5 .

$$
C=C_{o} \times F C_{L J} \times F C_{P A} \times F C_{H S} \times F C_{U K}
$$

Keterangan:

$C=$ Kapasitas $(\mathrm{smp} / \mathrm{jam})$

$C_{o}=$ Kapasitas dasar (smp/jam)

$F C_{L J}=$ Nilai penyetaraan pengaruh lebar jalan

$F C_{P A}=$ Nilai penyetaraan pengaruh pemisah arah (hanya untuk jalan tak terbagi)

$F C_{H S}=\quad$ Nilai penyetaraan pengaruh hambatan samping

$F C_{U K}=$ Nilai penyetaraan terhadap jumlah penduduk

\subsubsection{Derajat Kejenuhan}

Derajat kejenuhan $(D S)$ yakni rasio antara arus lalu lintas dengan kapasitas ruas jalan (Hera Widyastuti et al., 2019). Nilai derajat kejenuhan dapat diketahui menggunakan persamaan 10. Dikutip melalui Fadriani dan Syah (2019) (H. Widyastuti et al., 2019), apabila nilai derajat kejenuhan mendekati angka nol maka arus di ruas jalan tersebut semakin tidak jenuh, namun apabila mendekati angka satu maka sebaliknya. Nilai derajat kejenuhan dapat diperoleh menggunakan persamaan 6 .

$$
D S=\frac{V}{C}
$$

\subsubsection{Tingkat Pelayanan Jalan}

Tingkat pelayanan jalan (level of service) yakni rasio antara volume lalu lintas dengan kapasitas jalan di ruas jalan tersebut (Dipahada, Parman, \& Putro, 2014). Disadur melalui Imarianto, Pandulu, \& Arifianto (2017), nilai tingkat pelayanan jalan mampu menunjukkan kelayakan suatu ruas jalan dalam menampung volume lalu lintas yang ada. Kualitas tingkat pelayanan jalan dapat dilihat pada Tabel 2.

Tabel 2. Nilai Tingkat Pelayanan

\begin{tabular}{cc}
\hline Kualitas & Rasio volume/kapasitas \\
\hline A & 0 hingga 0,19 \\
B & 0,20 hingga 0,44 \\
C & 0,45 hingga 0,74 \\
D & 0,75 hingga 0,84 \\
E & 0,85 hingga 1,0 \\
F & Lebih dari 1 \\
\hline
\end{tabular}

Sumber: Wie, Lefrandt, \& Pandey, p. 232 (2019)

\section{Hasil dan Pembahasan}

\subsection{Analisis Kinerja Ruas Jalan dengan On-Street Parking}

Pada analisis ini, perhitungan yang dilakukan yaitu menghitung volume lalu lintas, hambatan samping, kecepatan setempat dan rata-rata ruang, kecepatan arus bebas, serta kapasitas jalan yang terpengaruh oleh aktivitas parkir pada badan jalan. 


\subsubsection{Volume Lalu Lintas}

Dari Gambar 2 didapatkan bahwa volume lalu lintas terpadat berada pada pukul 16.15 hingga 17.15 WIB yaitu sebesar $1620 \mathrm{smp} / \mathrm{jam}$. Sehingga, volume lalu lintas yang digunakan untuk kedua lajur tersebut adalah $1620 \mathrm{smp} / \mathrm{jam}$.

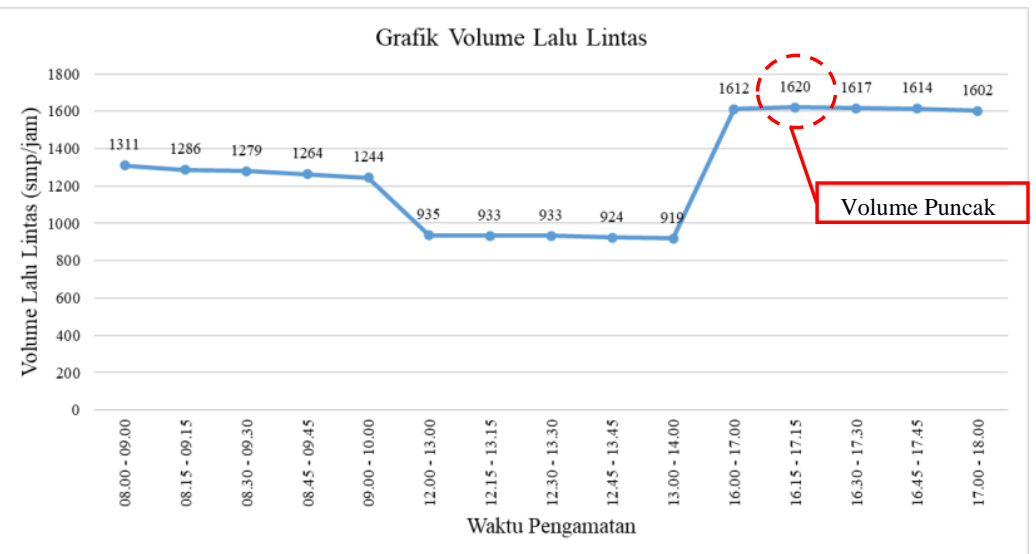

Gambar 2. Grafik Volume Lalu Lintas Kedua Ruas Jalan

\subsubsection{Hambatan Samping}

Kegiatan disekitar jalan merupakan salah satu pemicu masalah kemacetan di sekitar Pasar Jaya Ciracas. Aktivitas ini mempengaruhi kapasitas serta kecepatan kendaraan di ruas jalan. Jenis hambatan samping yang terdapat disekitar Pasar Jaya Ciracas diantaranya adalah pejalan kaki, kendaraan yang berhenti dan parkir, kendaraan bermotor yang masuk dan keluar dari sisi jalan, serta arus kendaraan lambat. Disadur melalui UU No. 22 Tahun 2009 Pasal 116 ayat (2) menyebutkan bahwa pengemudi perlu memperlambat gerak kendaraannya apabila: menemui kendaraan umum yang sedang manaikkan atau menurunkan penumpang, menemui kendaraan tidak bermotor (unmotorized), dan mendapati pejalan kaki yang hendak menyeberang. Sehingga, berdasarkan kondisi tersebut dengan kondisi umum daerah komersial disertai aktivitas pasar di samping jalan, maka kategori hambatan samping yang digunakan adalah terlalu tinggi (ST).

\subsubsection{Kecepatan Rata-Rata Ruang}

Pada analisis ini, segmen jalan yang digunakan adalah sepanjang 30 meter karena panjang tersebut masih berada dalam jangkauan pandang mata pengamat, jumlah waktu pengamatan selama 6 jam, dan jumlah waktu tempuh adalah 86,55 detik atau 0,024 jam untuk ruas Jalan Raya Ciracas menuju Jalan Raya Bogor sementara 81,91 detik atau 0,023 jam untuk ruas Jalan Raya Bogor menuju Jalan Raya Ciracas. Maka dapat diperoleh kecepatan rata-rata ruang sebagai berikut:

Untuk ruas Jalan Raya Ciracas menuju Jalan Raya Bogor

$$
V s=\frac{6 \times 0,03}{0,024}=7,5 \mathrm{~km} / \mathrm{jam}
$$

Untuk ruas Jalan Raya Bogor menuju Jalan Raya Ciracas

$$
V S=\frac{6 \times 0,03}{0,023}=7,83 \mathrm{~km} / \mathrm{jam}
$$

Berdasarkan perhitungan didapatkan nilai kecepatan rata-rata ruang untuk ruas Jalan Raya Ciracas menuju Jalan Raya Bogor sebesar 7,50 km/jam sementara untuk ruas Jalan Raya Bogor menuju Jalan Raya Ciracas sebesar 7,83 km/jam. Disadur melalui Peraturan Pemerintah Republik Indonesia No. 26 Tahun 1985 Pasal 9 Ayat (1) dikatakan bahwa jalan lokal primer dirancang 
dengan kecepatan rencana sedikitnya $20 \mathrm{~km} / \mathrm{jam}$. Sehingga terdapat perbedaan sebesar 60,85 hingga 62,5 persen dari kecepatan rencana minimum.

\subsubsection{Kecepatan Arus Bebas}

Berdasarkan persamaan 2 dengan nilai kecepatan arus bebas dasar sebesar $42 \mathrm{~km} / \mathrm{jam}$, adaptasi kecepatan terhadap lebar jalan sebesar $-2,7 \mathrm{~km} / \mathrm{jam}$, nilai penyetaraan terhadap hambatan samping sebesar 0,73 , dan nilai penyetaraan terhadap jumlah penduduk sebesar 1,03, maka didapatkan nilai kecepatan arus bebas sebagai berikut:

$$
\begin{gathered}
V_{B}=(4,2+(-2,7)) \times 0,73 \times 1,03 \\
V_{B}=29,55 \mathrm{smp} / \mathrm{jam}
\end{gathered}
$$

Dari hasil perhitungan dapat diketahui bahwa kecepatan pada tingkat arus nol (tidak terganggu oleh kendaraan bermotor lainnya) di lokasi yang ditinjau adalah $29,55 \mathrm{~km} / \mathrm{jam}$. Disadur melalui Peraturan Pemerintah Republik Indonesia No. 26 Tahun 1985 Pasal 9 Ayat (1) dikatakan bahwa jalan lokal primer dirancang dengan kecepatan rencana sedikitnya $20 \mathrm{~km} / \mathrm{jam}$. Sehingga nilai kecepatan pada tingkat arus nol untuk lokasi yang ditinjau memenuhi peraturan tersebut.

\subsubsection{Kapasitas Ruas Jalan}

Mengacu pada persamaan 5 dengan nilai kapasitas dasar sebesar $2900 \mathrm{smp} / \mathrm{jam}$ untuk jalan tipe $2 / 2$ TT, nilai penyetaraan pengaruh lebar jalan sebesar 0,88 , nilai penyetaraan akibat pengaruh pemisah arah sebesar 1, nilai penyetaraan akibat hambatan samping sebesar 0,73 , dan nilai penyetaraan terhadap jumlah penduduk sebesar 1,04, maka didapatkan nilai kapasitas ruas jalan sebagai berikut:

$$
\begin{gathered}
C=2900 \times 0,88 \times 1 \times 0,73 \times 1,04 \\
C=1944 \mathrm{smp} / \mathrm{jam}
\end{gathered}
$$

Dari hasil perhitungan didapati bahwa ruas jalan di lokasi yang ditinjau hanya mampu menampung volume lalu lintas sebesar $1944 \mathrm{smp} / \mathrm{jam}$. Apabila nilai volume lalu lintas melebihi nilai kapasitas tersebut maka dapat berpengaruh kepada tingkat pelayanan jalan dari ruas jalan tersebut.

\subsection{Analisis Tingkat Pelayanan Jalan dengan On-Street Parking}

Pada tahap ini, perhitungan yang dilakukan adalah menghitung kepadatan jalan, derajat kejenuhan serta mengklasifikasikan tingkat pelayanan jalan dari ruas jalan yang diteliti.

\subsubsection{Kepadatan Jalan}

Dari hasil perhitungan dapat diketahui bahwa ruas jalan yang ditinjau dapat ditempati sekitar 212 mobil penumpang per kilometer untuk dua arah. Apabila jumlah kendaraan melebihi nilai kepadatan jalan tersebut maka kendaraan akan mulai sulit untuk bergerak.

\subsubsection{Derajat Kejenuhan dan Tingkat Pelayanan Jalan}

Berdasarkan Gambar 3, nilai v/c ratio untuk kedua ruas jalan disekitar Pasar Jaya Ciracas adalah sebesar 0,83. Nilai v/c rasio pada ruas jalan di area Pasar jaya Ciracas tidak melebihi angka satu maka jalan yang ditinjau masih memenuhi syarat (belum melebihi kapasitas) sehingga tidak terjadi penurunan kualitas pada pergerakan arus lalu lintas. Dengan nilai v/c ratio sebesar 0,83 maka ruas Jalan Raya Ciracas dikategorikan memiliki tingkat pelayanan D. Meskipun nilai v/c rasio masih dibawah angka satu, namun disadur melalui Kementerian Perhubungan Republik Indonesia (2006), dikatakan bahwa jalan dengan sistem jaringan lokal primer memiliki tingkat pelayanan sekurangkurangnya adalah C. Sehingga tingkat pelayanan jalan disekitar Pasar Jaya Ciracas sudah tidak memenuhi kriteria tersebut. 


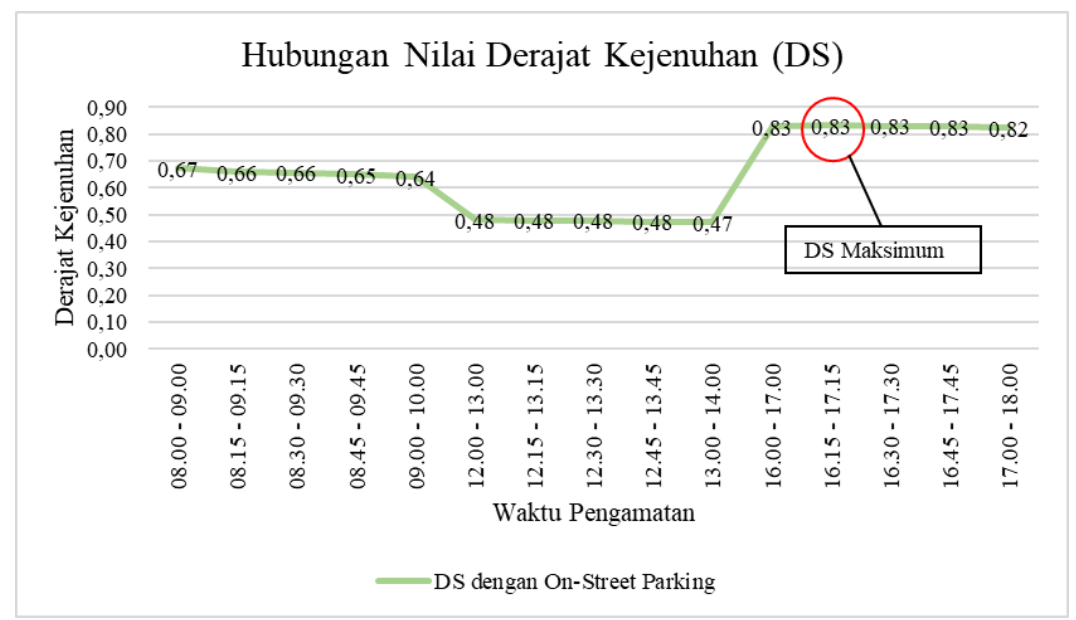

Gambar 3. Grafik Hubungan Derajat Kejenuhan (DS)

\subsection{Skenario Kinerja Ruas Jalan dan Tingkat Pelayanan Jalan tanpa On-Street Parking}

Hasil pengamatan yang sudah dilakukan di ruas Jalan Raya Ciracas merupakan data pengamatan yang dipengaruhi oleh adanya kegiatan parkir pada badan jalan. Sehingga kinerja ruas jalan yang dianalisis adalah kinerja ruas jalan dengan pengaruh parkir pada badan jalan. Selanjutnya dilakukan analisis dengan membuat skenario kinerja ruas jalan apabila tidak dipengaruhi oleh aktivitas parkir pada badan jalan untuk mengetahui kinerja ruas jalan yang ditinjau apabila kegiatan on-street parking ditiadakan. Nilai kinerja ruas jalan tanpa adanya parkir pada badan jalan dapat dihitung menggunakan volume lalu lintas yang sama seperti dengan adanya parkir pada badan jalan dengan perbedaan terletak pada lebar lajur lalu lintas serta lebar bahu efektif jalan.

Pada perhitungan kinerja ruas jalan tanpa adanya parkir pada badan jalan, nilai lebar jalur lalu lintas serta lebar bahu efektif diubah menjadi nilai lebar bahu jalan sebenarnya (lebar jalan dan bahu apabila tidak terganggu kegiatan parkir pada badan jalan). Selain itu nilai hambatan samping frekuensi kejadian parkir juga tidak diperhitungkan. Berikut merupakan hasil analisis kinerja ruas jalan tanpa pengaruh kegiatan parkir pada badan jalan:

Tabel 3 Skenario Kinerja Ruas Jalan dan Tingkat Pelayanan tanpa On-Street Parking Skenario Kinerja Ruas Jalan tanpa On-Street Parking

\begin{tabular}{ll}
\hline Volume Lalu Lintas & $1620 \mathrm{smp} / \mathrm{jam}$ \\
Hambatan Samping & Sedang (M) \\
Kecepatan Rata-Rata Ruang & Untuk Jalan Raya Ciracas menuju Jalan \\
& Raya Bogor sebesar 7,50 km/jam \\
& sementara untuk Jalan Raya Bogor \\
& menuju Jalan Raya Ciracas sebesar 7,83 \\
& $\mathrm{km} / \mathrm{jam}$ \\
& $36,43 \mathrm{~km} / \mathrm{jam}$ \\
Kecepatan Arus Bebas & $2370 \mathrm{smp} / \mathrm{jam}$ \\
\hline
\end{tabular}

Kapasitas Ruas Jalan $2370 \mathrm{smp} / \mathrm{jam}$

Kepadatan Jalan Skenario Tingkat Pelayanan Jalan tanpa On-Street Parking

Derajat Kejenuhan dan Tingkat Pelayanan Jalan
212 mobil penumpang per kilometer

Derajat kejenuhan sebesar 0,68 dengan tingkat pelayanan jalan berada pada kualitas C 


\section{Kesimpulan}

Berdasarkan hasil penelitian yang sudah dilakukan dapat ditarik kesimpulan bahwa adanya aktivitas parkir pada badan jalan mempengaruhi kinerja jalan disekitar Pasar Jaya Ciracas. Hal tersebut dapat terjadi karena lebar jalur lalu lintas efektif tidak terganggu oleh kegiatan parkir pada badan jalan serta nilai kategori hambatan samping yang berubah dari terlalu tinggi menjadi sedang. Kemudian, berdasarkan hasil perhitungan, didapatkan nilai tingkat pelayanan pada ruas jalan sekitar Pasar Jaya Ciracas apabila terdapat parkir pada badan jalan adalah D. Sementara itu, apabila aktivitas parkir pada badan jalan ditiadakan maka tingkat pelayanan jalan yang dihasilkan berada pada kualitas C. Sehingga, tingkat pelayanan jalan disekitar area Pasar Jaya Ciracas dengan sistem jaringan jalan lokal primer sekurang-kurangnya adalah $\mathrm{C}$ dapat terpenuhi. Bersumber pada hasil pengkajian yang telah dilakukan, nilai tingkat pelayanan jalan pada ruas jalan yang diteliti memburuk disebabkan karena terdapat penurunan kapasitas jalan akibat aktivitas parkir pada badan jalan. Sehingga dibutuhkan adanya tindakan tegas terkait dengan pengendalian parkir agar tidak mengganggu kegiatan lalu lintas pada jalan tersebut.

\section{Daftar Pustaka}

Boediningsih, W. (2011). Dampak Kepadatan Lalu Lintas terhadap Polusi Udara Kota Surabaya. Jurnal Fakultas Hukum, 119-137.

Dipahada, R., Parman, S., \& Putro, S. (2014). Analisis Level of Service (LOS) dalam Mengantisipasi Kemacetan Lalu Lintas Menggunakan SIG di Jalan Utama Kecamatan Kota Kendal. Geo-Image, 1-7.

Direktorat Jenderal Bina Marga. (2014). Pedoman Kapasitas Jalan Indonesia. Jakarta: Departemen Pekerjaan Umum.

Fadriani, H., \& Syah, A. I. (2019). Pengaruh Pedagang Kaki Lima di Badan Jalan terhadap Kecepatan dan Kapasitas Jalan. Jurnal Online Sekolah Tinggi Teknologi Mandala, 1-7.

Imarianto, G., Pandulu, G. D., \& Arifianto, A. K. (2017). Analisa Tingkat Pelayanan Jalan pada Ruas Jalan Gajayana Kecamatan Lokokwaru Kota Malang. Jurnal Penelitian Teknik Sipil dan Teknik Kimia, 64-74.

Kayori, R. F., Sendow, T. K., Jefferson, L., \& Manopo, M. R. (2013). Analisa Derajat Kejenuhan Akibat Pengaruh Kecepatan Kendaraan pada Jalan Perkotaan di Kawasan Komersil. Jurnal Sipil Statik, 608-615.

Kementerian Perhubungan Republik Indonesia. (2006, Maret 6). Peraturan Menteri Perhubungan Nomor KM 14 Tahun 2006. Retrieved from Direktorat Jenderal Perhubungan Darat: http://hubdat.dephub.go.id/km/tahun-2006/222-km-14-tahun-2006-ttg-manajemen-danrekayasa-lalu-lintas-di-jalan

Lestari, F. A., \& Apriyani, Y. (2014). Analisis Dampak Lalu Lintas Akibat Adanya Pusat Perbelanjaan di Kawasan Pasar Pagi Pangkalpinang terhadap Kinerja Ruas Jalan. Jurnal Forum Profesional Teknik Sipil, 32-44.

Mustikarani, W., \& Suherdiyanto. (2016). Analisis Faktor-Faktor Penyebab Kemacetan Lalu Lintas di Sepanjang Jalan H Rais A Rahman (Sui Jawi) Kota Pontianak. Edukasi: Jurnal Pendidikan, 143-145. 
Pemerintah Republik Indonesia. (1985, May 31). Undang-Undang No. 26 Tahun 1985 tentang Jalan. Retrieved from Database Peraturan BPK RI:

https://peraturan.bpk.go.id/Home/Details/64596/pp-no-26-tahun-1985

Sari, N. M., Oktaviani, \& Novia, A. (2015). Tinjauan Kecepatan Kendaraan pada Wilayah Zona Selamat Sekolah (ZoSS) di Kota Padang. Annual Civil Engineering Seminar , 383 - 389.

Sulastri, \& Firdaus, O. (2018). Pengaruh Pergerakan Angkutan Umum Terhadap Kelancaran Arus Lalu Lintas. FROPIL (Forum Profesional Teknik Sipil), 80-91.

Syaputra, R., Sebayang, S., \& Herianto, D. (2016). Pengaruh Hambatan Samping Terhadap Kinerja Lalu Lintas Jalan Nasional (Studi Kasus Jalan Proklamator Raya-Pasar Bandarjaya Plaza). Jurnal Rekayasa Sipil dan Desain, 441-454.

TomTom International BV. (n.d.). Jakarta Traffic Report . Retrieved from TomTom Traffic Index: https://www.tomtom.com/en_gb/traffic-index/jakarta-traffic/

Utami, A., \& Widyastuti, H. (2019). Model Panjang Antrian Kendaraan pada Perlintasan Sebidang Tanpa Palang Pintu (Studi Kasus: Perlintasan Sebidang Jl. Gayung Kebonsari Surabaya). Jurnal Aplikasi Teknik Sipil, 17(1), 27. https://doi.org/10.12962/j2579-891x.v17i1.4693

Widyastuti, H., Utami, A., \& Putra, M. (2019). Model of Queuing in the Railway Level Crossings (Case Study: Railway Level Crossings in Jemursari Surabaya). Atlantis Press, 186(Apte 2018), 225-232. https://doi.org/10.2991/apte-18.2019.41

Widyastuti, H., Utami, A., \& Dzulfiqar, Z. M. (2019). Model of queuing in the railway level crossing (case study: Imam Bonjol railway level crossing in Blitar). IOP Conference Series: Materials Science and Engineering, 650(1). https://doi.org/10.1088/1757899X/650/1/012053

Wie, N. R., Lefrandt, L. I., \& Pandey, S. V. (2019). Kajian Efektifitas Penerapan Zona Selamat Sekolah (Zoss) Di Kota Tomohon (Studi Kasus: SD Negeri 2 Tomohon Dan SD Lentera Harapan Tomohon). Jurnal Sipil Statik, 229-236.

Yeung, J. S., Wong, Y. D., \& Secadiningrat, J. R. (2015). Lane-harmonised Passenger Car Equivalents for Heterogeneous Expressway Traffic. Transportation Research Part A, 363. 